University of Nebraska - Lincoln

DigitalCommons@University of Nebraska - Lincoln

9-15-2009

\title{
A Short Report: Word-Level Phonological and Lexical Characteristics Interact to Influence Phoneme Awareness
}

Tiffany Hogan

University of Nebraska - Lincoln, thogan2@unl.edu

Follow this and additional works at: https://digitalcommons.unl.edu/specedfacpub

Part of the Special Education and Teaching Commons

Hogan, Tiffany, "A Short Report: Word-Level Phonological and Lexical Characteristics Interact to Influence Phoneme Awareness" (2009). Special Education and Communication Disorders Faculty Publications. 12. https://digitalcommons.unl.edu/specedfacpub/12

This Article is brought to you for free and open access by the Department of Special Education and Communication Disorders at DigitalCommons@University of Nebraska - Lincoln. It has been accepted for inclusion in Special Education and Communication Disorders Faculty Publications by an authorized administrator of DigitalCommons@University of Nebraska - Lincoln. 


\title{
A Short Report: Word-Level Phonological and Lexical Characteristics Interact to Influence Phoneme Awareness
}

\author{
Tiffany P. Hogan \\ University of Nebraska - Lincoln
}

\begin{abstract}
In this study, we examined the influence of word-level phonological and lexical characteristics on early phoneme awareness. Typically-developing children, ages 61-78 months, completed a phoneme-based, odd-one-out task that included consonant-vowel-consonant word sets (e.g., "chair-chain-ship") that varied orthogonally by a phonological characteristic, sound-contrast similarity (similar vs. dissimilar), and a lexical characteristic, neighborhood density (dense vs. sparse). In a subsample of the participants - those with the highest vocabularies - results were in line with a predicted interactive effect of phonological and lexical characteristics on phoneme awareness performance: word sets contrasting similar sounds were less likely to yield correct responses in words from sparse neighborhoods than words from dense neighborhoods. Word sets contrasting dissimilar sounds were most likely to yield correct responses regardless of the words' neighborhood density. Based on these findings, theories of early phoneme awareness development should consider both word-level (e.g., phonological and lexical characteristics) and child-level (e.g., vocabulary knowledge) influences on phoneme awareness performance. Attention to these word-level item influences is predicted to result in more sensitive and specific measures of reading risk.
\end{abstract}

The causal relation between phoneme awareness and initial reading achievement has been well documented (for reviews, see Adams, 1990; Gillon, 2004). Specifically, phoneme awareness measured in young prereaders, has been found to predict future reading abilities (Catts, Fey, Zhang, \& Tomblin, 2001; Olofsson \& Wall, 1980; Mann, 1984; Share, Jorm, Maclean, \& Matthews, 1984; Torgesen, Wagner, \& Rashotte, 1994; Yopp, 1988). Furthermore, experimental studies have shown that programs that stimulate phoneme awareness enhance word reading skills (e.g., Bradley \& Bryant, 1983; Elbro \& Petersen, 2004). Given the connection between phoneme awareness and reading outcomes, tests of phoneme awareness in preschool/kindergarten have been used to identify who are at risk for reading impairment. Subsequently, early phoneme awareness intervention is provided to the identified, at-risk children with the goal of preventing or reducing later reading difficulties.

One significant hindrance to the goal of early identification and intervention for reading impairment is that tests of phoneme awareness, although related to reading achievement, provide mediocre sensitivity and specificity for categorizing those children who are at risk versus those who are not. It is not the case that a low score on a phoneme awareness test in preschool or kindergarten is an absolute indicator of later reading risk. Correlations between phoneme awareness and word reading are consistently in the moderate range (e.g., Scarborough, 2005). In a meta-analyses sampling of 35 research reports, Swanson, Trainin, Necoechea, \& Hammill (2003) found phoneme awareness to be correlated to real and pseudo-word reading in the range of .42 to .55 . Heath and Hogben (2004) examined the predictive power of phoneme awareness to future reading in kindergarten children with good and poor awareness. They reported that only approximately one-fourth of all of those who scored in the lower quartile on a phoneme awareness measure had a reading disability at the end of second grade. Clearly it is unacceptable to over identify $75 \%$ of the children as at risk for reading impairments.

Why is there so much error in tests of phoneme awareness? One potential source is lack of consideration of word-level phonological and lexical characteristics when choosing test words. At present, words on phoneme awareness tests are often chosen because they are familiar to young children. This is a reasonable approach used to avoid testing error (i.e., a child may miss a test item because he/she didn't know the word or could not remember the word, not because he/she had poor phoneme awareness). However, a data-driven, theory- 
based selection of test words is likely to increase the sensitivity and specificity of phoneme awareness tests. To illustrate, if specific phoneme awareness test items (i.e., words or groups of words) are found to be consistently incorrect in the early grades for those children who go on to have word reading difficulty, those test words would be used to construct a test of phoneme awareness that is sensitive and specific to future word reading impairment. Moreover, by determining word-level characteristics that increase test sensitivity, one could create a pool of test items with similar characteristics. Such a pool would allow for the creation of multiple test forms to measure phoneme awareness at one time point or as it changes over time. An accurate measure of static and dynamic phoneme awareness abilities is imperative for current models of early identification (e.g., response to intervention) for reading risk.

Phoneme awareness theories offer insight into the word-level phonological and lexical characteristics that should be considered when attempting to create more sensitive phoneme awareness tests. Inherent to these theories is the premise that the amount of phonemic detail contained in one's form representations primarily influences performance on tests of phoneme awareness. A form representation is one's representation of the sounds in a given word. Two types of form representations include the sounds in a given word (e.g., Luce, Goldinger, Auer, \& Vitevitch, 2000): a) the phonological representation which is formed by assembling the individual sounds in a word or nonword, b) the lexical representation which is a mental representation - or abstraction - of the combination of sounds that comprise a word. Note that words contain both types of representations, phonological and lexical. The phonological deficit hypothesis (Catts, 1986, 1989; Elbro, 1996; Elbro, Neilsen, \& Petersen, 1994; Fowler, 1991; Shankweiler \& Liberman, 1978; Swan \& Goswami, 1997) focuses on intact phonological representations as a fundamental component of phoneme awareness. In contrast, the lexical restructuring model (Metsala \& Walley, 1998; Walley, Metsala, \& Garlock, 2003) posits a link between lexical representations and phoneme awareness. This study will use these theories' predictions to simultaneously investigate the impact of word-level phonological and lexical characteristics on phoneme awareness performance in typically developing children.

\section{Phonological Deficit Hypothesis: Focus on Phonological Characteristics}

The phonological deficit hypothesis states that poor readers have problems perceiving and/or storing phonological information which, in turn, disrupts formation of the sounds assembled to comprise phonological representations (Catts, 1986, 1989; Elbro, 1996; Elbro et al., 1994; Fowler, 1991; Shankweiler \& Liberman, 1978;
Swan \& Goswami, 1997). Less specified phonological representations lead to deficient phoneme awareness and faulty sound to letter correspondences, both of which are needed to learn to read. This hypothesis highlights the need to examine the influence of soundbased phonological representations and phoneme awareness performance. Indeed, past studies have revealed that the sounds in words influence rates of performance accuracy on phoneme awareness tasks (e.g., Treiman, Broderick, Tincoff, \& Rodriguez, 1998; Yavas \& Core, 2001). Catts, Wilcox, Wood-Jackson, Larrivee, and Scott (1996) showed that typically developing kindergarten children were less accurate in an odd-oneout task when sounds were similar (i.e., differing by few sound characteristics: distinctive features; Chomsky \& Halle, 1968) than when sounds were dissimilar: children were correct on $57 \%$ of the items that contrasted 'similar' sounds, for example initial /f/ and $/ \theta /$, "fan-thumb-five," and $64 \%$ correct on items that contrasted 'dissimilar' sounds, for example /g/ and / s/, "gate-sun-soap." In another study (Yavas \& Core, 2001), sound similarity was categorized by sound sonority instead of distinctive feature differences. Sonority refers roughly to the degree of stricture in the vocal tract (Chin, 1996). Results showed that more sonorous sounds were harder to delete at the end of a word compared to less sonorous sounds, which tended to be easier to delete (see also Ho \& Bryant, 1997). They hypothesized that this effect was due to coarticulation; a more sonorous sound co-articulates more fluidly with its preceding vowel. These results highlight the impact of individual sounds on phoneme awareness performance. None of these studies, however, considered, or controlled for, the potential influence of lexical representations on phoneme awareness performance even though the stimuli were real words, containing both phonological and lexical representations.

\section{Lexical Restructuring Model: Focus on Word-Level Lexical Characteristics}

According to the lexical restructuring model (Metsala \& Walley, 1998; Walley et al., 2003), phoneme awareness is a product of the segmental restructuring of lexical representations that arises as a result of a child's rapidly growing vocabulary. More specifically, it is proposed that when a child's lexicon is small, holistic representations are sufficient to differentiate each word from every other word. These representations may include only minimal information about phonemes. As new words are acquired, underlying lexical representations must become more phonemically detailed in order to differentiate newly learned targets from the existing representations in the lexicon. Metsala and Walley (1998) argue that representations undergo lexical restructuring on an individual basis. Thus, lexical restructuring is not 
a system-wide process affecting all words in the lexicon equally. It is thought that lexical characteristics predict which words will undergo restructuring.

One lexical characteristic that is predicted to influence restructuring is neighborhood density. Neighborhood density relates to the number of similar sounding words in the lexicon (e.g., Luce \& Pisoni, 1998). In particular, a neighborhood contains all the words differing by one phoneme substitution, deletion, or addition. For example, neighbors of sit include sip, sat, hit, it, and spit and neighbors of these include words such as those, tease, and ease. Words with many neighbors reside in 'dense' neighborhoods. Alternatively, words with few neighbors reside in 'sparse' neighborhoods. In total, sit has 36 neighbors and resides in a dense neighborhood, whereas these only has 9 neighbors and resides in a sparse neighborhood (Storkel \& Morrisette, 2002). The lexical restructuring model proposes that words in dense neighborhoods are more likely to have segmentally detailed representations when compared to words in sparse neighborhoods. This is because of the greater potential for overlap among words in a dense neighborhood. Because words from dense neighborhoods have many similar sounding neighbors, these words are hypothesized to contain more phonemic detail. Due to their increase in phonemic detail, words from dense neighborhoods should show the highest accuracy on phoneme awareness tests.

Several empirical studies have confirmed a link between word-level neighborhood density and performance on a phoneme awareness test. Metsala (1999) found that preschool children ages 3-4 years old performed better on a spoken phoneme blending task when the test words came from dense neighborhood. Likewise, De Cara and Goswami (2003) revealed that 5 year olds were better at making rhyme judgments about words from dense neighborhoods. However, these studies did not explicitly consider the influence of phonological characteristics on phoneme awareness performance.

\section{Vocabulary Effects}

In the DeCara and Goswami (2003) study neighborhood density effects on phoneme awareness were only found in those children with high vocabularies. Recall that the lexical restructuring model predicts that a word's neighborhood density influences the amount of phonemic detail contained in that word. Words with many neighbors are more likely to contain phonemic detail that may be useful when contrasting sounds in a phoneme awareness task. As children add words to their vocabularies, phonological neighborhoods expand (Charles-Luce \& Luce, 1990). Thus, it follows that neighborhood density effects may be more robust in those with higher vocabularies.
Study Questions and Predictions

The phonological deficit hypothesis highlights the influence of word-level phonological characteristics on performance, whereas the lexical restructuring model predicts that word-level lexical characteristics will influence performance. A limitation of past studies is the consideration of only one word-level characteristic, either phonological or lexical, when words contain both phonological and lexical representations (Vitevitch, 2003). The purpose of this study was to examine the potential interactive influence of word-level phonological and lexical characteristics on early phoneme awareness in typically developing children. Mirroring the Catts et al. (1996) study, a phoneme-based, odd-one-out task was created to include word sets varying by a phonological characteristic (i.e., similar vs. dissimilar sound contrasts). Additionally, the task included words differing in neighborhood density, the lexical characteristic of interest. Resultant was an orthogonal design in which test word sets varied both in sound-contrast similarity (similar vs. dissimilar) and in neighborhood density (dense vs. sparse). Four word-set conditions were created: a) similar sound-contrast/dense neighborhood, b) similar sound-contrast/sparse neighborhood, c) dissimilar sound-contrast/dense neighborhood, and d) dissimilar sound-contrast/sparse neighborhood. It was hypothesized that performance accuracy would reveal an interaction: word-level phonological characteristics would influence performance as shown in past studies - words sets with dissimilar sound-contrasts would show higher accuracy than sets with similar sound-contrasts - but the differences in accuracy would be influenced by the word-level lexical characteristic, neighborhood density. The most accurate performance would be shown for test word sets contrasting dissimilar sounds in words from dense and sparse neighborhoods, whereas the least accurate performance would be shown for test word sets contrasting similar sounds in words from sparse neighborhoods. It was predicted that dense words with more phonemic detail via lexical restructuring would provide more phoneme-specific information for contrasting similar sounds. It was predicted that those children with high vocabularies would show the strongest effect of neighborhood density on phoneme awareness performance - in line with the results of De Cara and Goswami (2003).

\section{Method}

\section{Participants}

Participants included 21 typically-developing children - 12 males and 9 females - ages 61-78 months $(M=69.76$ months, $S D=4.90)$ attending kindergarten in private schools located in mid- to high- socio-economic 
neighborhoods in the midwest and southwest portions of the United States of America. These children were a subset of a sample of 45 children who participated in a larger study of phoneme awareness. All were primary English speakers with no history of speech, language, or hearing deficits, per parent report. Table 1 contains descriptive information about the children in the study. Each passed a hearing screening (ASHA, 1997) and scored within the normal range on tests of expressive vocabulary, receptive vocabulary, productive phonology, nonverbal intelligence, phonological awareness, and print knowledge. Typically developing kindergarteners were chosen as participants for three reasons. First, a baseline of performance is required to contrast typical performance with impaired performance. Noted differences would lead to systematic selection of test words that are more sensitive and specific to reading risk. Second, children in kindergarten were chosen because their phoneme awareness should not yet be so heavily influenced by orthographic knowledge (Hogan, Catts, \& Little, 2005). Thirdly, the primary goal of early identification is to intervene before children fail. Kindergarten is an opportune time to determine reading risk as children are just beginning formal education in the United States.

\section{Stimuli}

Stimuli consisted of 40 consonant-vowel-consonant word sets varied orthogonally by sound-contrast, similar vs. dissimilar, and neighborhood density, dense vs. sparse. Each condition contained 10 word sets. Of the 10 in each set, 5 were selected to contrast initial sound and 5 were selected to contrast final sound. Placement of sound contrast was manipulated to avoid ceiling or floor effects (Catts et al., 1996).

In terms of sound-contrast, sounds were deemed similar or dissimilar based on the number of distinctive features (Chomsky \& Halle, 1968) separating them. For example, the sounds /f/ and /v/ only differ by voicing (i.e., 1 distinctive feature). Thus, a word set containing a 'similar' initial sound-contrast was "vote-fire-face." All sets in the 'similar sound-contrast' conditions contained sounds differing by 1 distinctive feature. Alternatively, a dissimilar sound-contrast was $/ \mathrm{n} /$ and $/ \mathrm{h} /$ (e.g., "nine-hole-head") which differed by 9 distinctive features. On average, word sets in the 'dissimilar soundcontrast' conditions contained sounds differing by 7.85 distinctive features $(S D=0.74$, range $=7-9)$.

Neighborhood density was calculated using the Hoosier Mental Lexicon, a 20,000 word electronic database (Nusbaum, Pisoni, \& Davis, 1984). A neighbor was defined as a word that differed by one phoneme addition, deletion, or substitution. Within each word set, words were selected to be dense or sparse, whereby dense words contained 10 or more word neighbors ( $M$ $=17.2, S D=4.32$, range 10-29) and sparse words contained 9 or fewer $(M=6.57, S D=1.79$, range 3-9). The examples above (i.e., "vote-fire-face", "nine-hole-head") contain words from dense neighborhoods; thus they were categorized as dense word sets. An example set containing words from sparse neighborhoods was, "house-knife-neck."

A conscious effort was made to select word sets that did not differ in ways that may have confounded the

Table 1. Demographic Data and Test Scores for Children in the Study $(n=21)^{1}$

\begin{tabular}{|c|c|c|c|c|}
\hline & $M$ & $S D$ & Minimum & Maximum \\
\hline Age in months & 61.76 & 4.90 & 61 & 78 \\
\hline Expressive vocabulary ${ }^{2}$ raw score & 74.05 & 13.37 & 53 & 101 \\
\hline Expressive vocabulary ${ }^{3}$ standard score & 114.00 & 15.13 & 89 & 145 \\
\hline Receptive vocabulary ${ }^{4}$ raw score & 79.67 & 12.90 & 63 & 104 \\
\hline Receptive vocabulary ${ }^{5}$ standard score & 114.19 & 11.55 & 98 & 133 \\
\hline Nonverbal intelligence ${ }^{6}$ quotient & 118.57 & 15.64 & 93 & 140 \\
\hline Productive phonology ${ }^{7}$ percentile & 55.38 & 19.15 & 11 & 78 \\
\hline Phonological awareness ${ }^{8}$ standard score & 114.45 & 2.29 & 109 & 118 \\
\hline Print knowledge ${ }^{9}$ standard score & 111.00 & 9.57 & 95 & 124 \\
\hline \multicolumn{5}{|c|}{$\begin{array}{l}{ }^{1} \text { Note that } 1 \text { participant left the study before completing the phonological awareness and print knowled } \\
\text { assessment. } \\
{ }^{2} \text { Expressive One Word Picture Vocabulary Test (Brownell, 2000a) raw score } \\
{ }^{3} \text { Expressive One Word Picture Vocabulary Test (Brownell, 2000a) standard score } \\
{ }^{4} \text { Receptive One Word Picture Vocabulary Test (Brownell, 2000b) raw score } \\
5 \text { Receptive One Word Picture Vocabulary Test (Brownell, 2000b) standard score } \\
{ }^{6} \text { Reynolds Intellectual Assessments Scales (Reynolds \& Kamphaus, 2002) nonverbal intelligence quotient } \\
{ }^{7} \text { Goldman Fristoe Test of Articulation - } 2 \text { (Goldman \& Fristoe, 2000) percentile } \\
{ }^{8} \text { Test of Preschool Early Literacy (Lonigan, Wagner, Torgesen, \& Rashotte, 2007) phonological awareness } \\
\text { subtest standard score } \\
{ }^{9} \text { Test of Preschool Early Literacy (Lonigan et al., 2007) print knowledge subtest standard score }\end{array}$} \\
\hline
\end{tabular}


four stimuli conditions. All words were deemed high frequency (>50) according to one of two databases (Kucera \& Francis, 1967; Moe, Hopkins, \& Rush, 1982). Moreover, words in the word sets did not differ by frequency according to condition. Likewise, sounds within each sound-contrast were selected to be as close as possible, if not the same sounds, across dense and sparse word sets.

Each word in the sets was audio recorded three times in a sound proof booth by a female native speaker of English. Of the three word tokens, the token with the most clarity and quality was chosen for each word. Sound durations were measured for the final word recordings. Word durations did not significantly differ by sound-contrast conditions (similar vs. dissimilar) or neighborhood density conditions (dense vs. sparse). Three native English speakers correctly transcribed the words under the same conditions as the study participants. Likewise, three cartoon, colored pictures were created or selected to represent each word. Six undergraduate/graduate students determined the picture most representative of each word. The pictures were standardized in size $(9.07 \times 9.03 \mathrm{~cm})$. Appendix A contains the 40 word sets by condition with corresponding word/condition specific data.

\section{Odd-One-Out Task}

The odd-one-out task was administered to participants individually by trained undergraduate/graduate students via a laptop computer in a quiet room in each participant's school. Auditory stimuli were played over desktop speakers. During the task, participants heard three words, one at a time, as a picture of each word appeared on the computer screen. Pictures were centered vertically on the screen; whereas, horizontally, the first picture was to the left of the screen, the next picture was in the center, and the last picture was to the right. Picture support was used in the task to alleviate working memory demands. Word/picture placement was randomized via experimental control software (Direct RT; Jarvis, 2007) because differences in difficulty have been found based on the place of the word containing the sound contrast (Catts et al., 1996). Items were presented in initial sound contrast and final sound contrast blocks randomized across participants across two sessions spaced an average of four days apart (range 1-7 days). Within a session, two blocks of 10 word sets were administered with a short break for reinforcement (e.g., sticker) between the testing blocks. Within blocks, the order of the word sets was randomized by the experimental control software.

Participants were read the following instructions: "Today we're going to play a listening game on the computer, but first I have to show you how to play the game. You're going to hear three words and see one pic- ture for each word. In this game, you'll figure out which word ends with a different sound than the other words. After you hear the three words, point to the picture with the different sound." Note that these instructions were used in the final sound contrast condition. The underlined word in the instructions changed to "starts" when the task was initial sound contrast.

To ensure that participants could complete the task, each was required to pass a training set. The training set consisted of six word sets. During the training, examiners provided corrective feedback. To continue to the experimental task, participants correctly answered 4 out of the six word sets correctly within three training sets. Those who didn't meet the training set were discontinued from this portion of the testing. Of 45 children participating in a larger study of phoneme awareness, 21 passed the training and completed the word sets above chance.

Reliability. Participant responses were video-recorded. Additionally, an examiner scored the participants' responses online. All scoring was double checked by another examiner. Procedural reliability was computed for $20 \%$ of the participants. A reliability judge viewed videos to determine if protocol administration and computer set-up was consistent across and within participants. Reliability was $91 \%$ ( $S D=7.7 \%$, range $83 \%$ $-100 \%)$.

\section{Results}

Before turning to planned analyses, a repeated measure ANOVA was employed to verify that sound contrast placement (initial vs. final) was not a significant factor that needed to be included in further analyses. The dependent measure was number correct out of a total of 20 word sets per condition, initial sound contrast and final sound contrast. Note that in each analysis for each variable the partial eta squared $\left(\eta_{\mathrm{p}}{ }^{2}\right)$ effect size was computed. This effect size can be interpreted much like a partial correlation in regression. Results revealed that performance on initial sound contrasts $(M=14.10$, $S D=3.06, S E M=.67)$ was more accurate compared to performance on final sound contrasts $(M=12.67, S D=$ $3.48, S E M=.76$ ); however the differences were not statistically significant, $F(1,20)=3.03, p=.097, \mathrm{\eta}_{\mathrm{p}}^{2}=.13$. As such, initial and final sound contrast data were collapsed for further analyses.

To examine the influence of vocabulary on phoneme awareness, participants were grouped as having relatively high or relatively low expressive vocabulary based on a median split of expressive vocabulary raw scores. This grouping procedure was in line with De Cara \& Goswami (2003) who also chose to parse participants according to a median split of vocabulary abilities. This delineation resulted in two groups: the low vocabulary group contained 11 participants, whereas the 
high vocabulary group contained 10 participants. The high vocabulary group had an average expressive vocabulary raw score of $85.40(S D=8.15, S E M=2.58$; standard score $M=126.6, S D=8.93, S E M=2.82$ ) and the low vocabulary group had an average expressive vocabulary raw score of $63.73(S D=7.18, S E M=2.17$; standard score $M=102.55, S D=9.10, S E M=2.74)$. The groups were significantly different in vocabulary as intended, $p$ $=.00$. However, the vocabulary groups were not significantly different in any descriptive characteristic except receptive vocabulary raw score, $p=.04$, and phonological awareness raw score and standard score, $p=.03$ and $p=.04$, respectively.

Data were submitted to a 2 within subject factor, sound-contrast (similar vs. dissimilar), $\times 2$ within subject factor, neighborhood density (dense vs. sparse), $\times 2$ between subject factor, vocabulary group (high vs. low), mixed ANOVA to examine the influence of both wordlevel phonological and lexical characteristics on phoneme awareness performance by vocabulary groups. The dependent variable was the number of correct word sets per the four orthogonally varied conditions. Results of the ANOVA revealed a near-significant 2-way interaction between sound-contrast and neighborhood density, $F(1,19)=4.28, p=.052, \eta_{\mathrm{p}}^{2}=.18$, qualified by a significant 3-way interaction between vocabulary group, sound-contrast, and neighborhood density ${ }^{1}, F(1,19)=$ $5.09, p=.036, \eta_{\mathrm{p}}^{2}=.21$. The group main effect did not reach significance, $F(1,19)=2.69, p=.117, \eta_{\mathrm{p}}^{2}=.12$. To examine significant contrasts, data were decomposed by group and separate repeated measures ANOVAs were completed. Figure 1 graphically displays data from participants in the high vocabulary group. A repeated measures ANOVA containing two within subjects factors

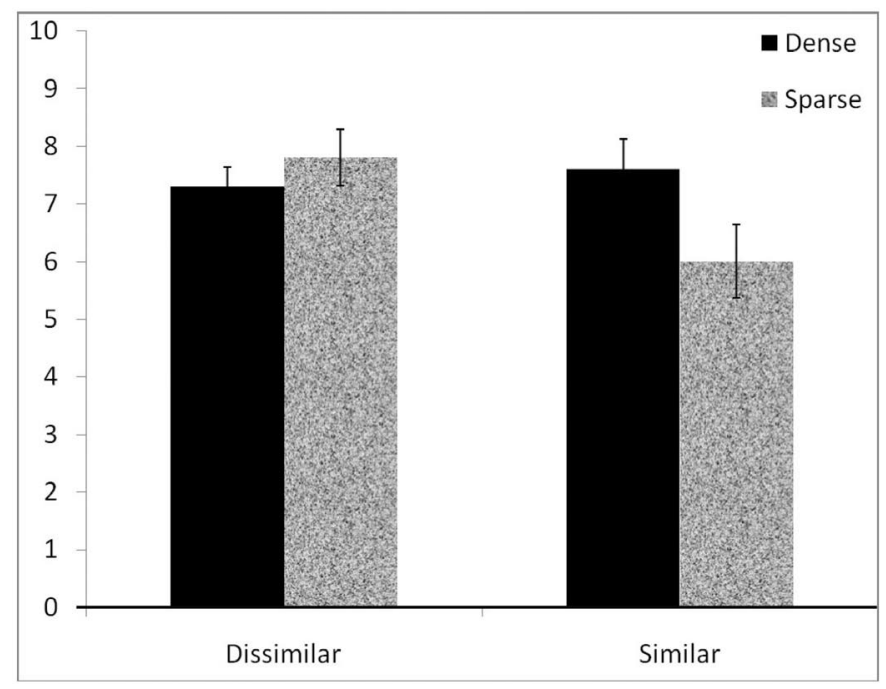

Figure 1. Number correct by test word conditions. Error bars represent the standard error of the mean. Graph includes data for participants in the high vocabulary group $(n=10)$. (sound-contrast: similar vs. dissimilar; neighborhood density: dense vs. sparse) revealed a significant twoway interaction between sound-contrast and neighborhood density, $F(1,9)=15.94, p=.003, \eta_{p}^{2}=.64$, including data from participants in the high vocabulary group. Repeated measures planned comparisons were than employed to determine significant contrasts. As predicted, high levels of accuracy were present when dissimilar sounds were contrasted, regardless of neighborhood density $(p=.23$, dissimilar - dense: $M=7.30, S D=1.06$, $S E M=.33$; dissimilar - sparse: $M=7.80, S D=1.55$, SEM $=.49$ ). The participants showed lower performance accuracy, as predicted, when contrasting similar sounds in words from sparse neighborhoods $(M=6.00, S D=1.06$, $S E M=.63)$ compared to their accuracy when contrasting similar sounds in dense neighborhoods $(p=.029$, similar - dense: $M=7.60, S D=1.65, S E M=.52)$. Participants did not significantly differ, however, on performance accuracy when contrasting similar sounds in words from sparse neighborhoods and when contrasting dissimilar sounds from dense neighborhoods $(p=.146)$. Figure 2 shows data from participants in the low vocabulary group. A repeated measures ANOVA containing two within subjects factors (sound-contrast: similar vs. dissimilar, neighborhood density: dense vs. sparse) revealed no significant main effects or interactions based on data from participants in the low vocabulary group.

Item analyses were conducted to confirm that word sets in each condition were contributing equally to the findings from all ANOVAs. The results were in line with the subjects analyses lending statistical support to the notion that the word-level characteristics were contributing to the findings as opposed to an anomalous word set.

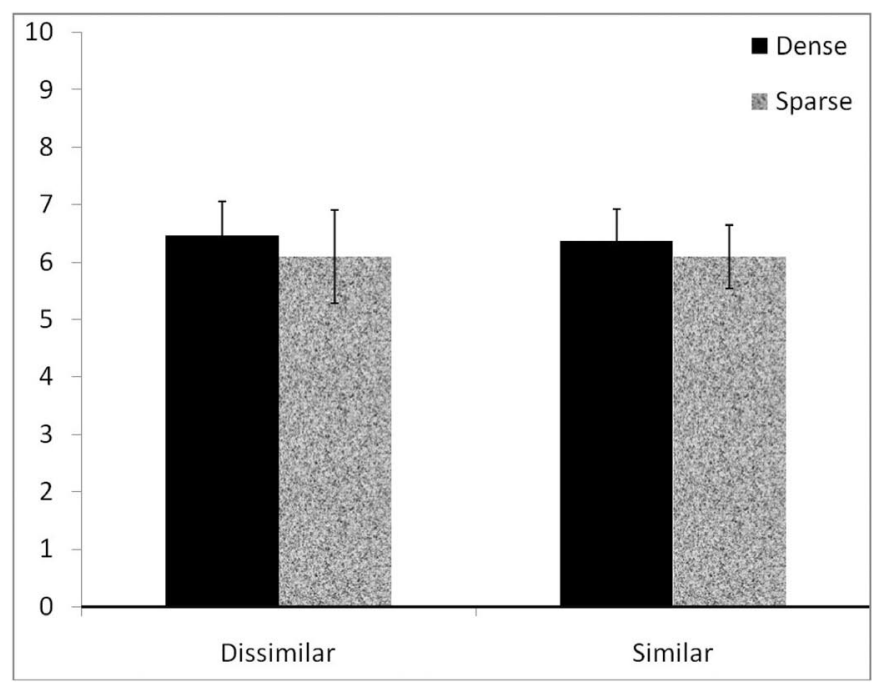

Figure 2. Number correct by test word conditions. Error bars represent the standard error of the mean. Graph includes data for participants in the low vocabulary group $(n=11)$. 


\section{Discussion}

This study examined the influence of word-level phonological and lexical characteristics on early phoneme awareness in typically developing children. The longterm goal of this line of inquiry is to find word-level item characteristics that will facilitate the creation of tests of phoneme awareness that are sensitive and specific to reading risk. The phonological deficit hypothesis (Catts, 1986, 1989; Elbro, 1996; Elbro et al., 1994; Fowler, 1991; Shankweiler \& Liberman, 1978; Swan \& Goswami, 1997) provided impetus for examining a phonological characteristic. Indeed, past studies have found that the phonological, sound-based, characteristics of words predictably influenced phoneme awareness performance (e.g., Catts et al., 1996; Treiman et al., 1998; Yavas \& Core, 2001). In this study the phonological characteristic of interest was sound similarity - the similarity of sounds to be contrasted in an odd-one-out task. The lexical restructuring model (Metsala \& Walley, 1998; Walley et al., 2003) highlighted the potential influence of neighborhood density, a lexical characteristic. Words with many similar sounding neighbors yield higher accuracy on phoneme awareness tasks (De Cara \& Goswami, 2003; Metsala, 1999) compared to works with fewer neighbors. This study was the first to examine the influence of both a phonological characteristic (i.e., sound similarity) and a lexical characteristic (i.e., neighborhood density) on phoneme awareness performance.

Results revealed a predicted interaction: similar sound contrasts were indeed difficult, but less so in dense words. Dissimilar sounds, which were easier to contrast, did not show a density effect. We interpret this interaction within a framework in which phoneme awareness performance is reliant on both the phonological representation (individual sounds) and the lexical representation (an abstraction of integrated sounds paired with meaning) that comprise a word. In the oddone-out task, individual sounds within words are compared, evoking each word's phonological representation. These contrasts, however, occur in the context of words with abstract, lexical representations tied to meaning. Dense words would have more phonemic detail via lexical restructuring making sound contrasts within dense words easier than making the same contrasts in sparse words. In this scenario, the act of consciously reflecting on the sounds in words activates the phonological representation - the individual sounds in words - and those sounds are then filtered through the lexical representation of a word giving rise to a dense word performance advantage. However, it is reasonable to hypothesize that the phonological representation in a phoneme awareness task involving real words is never activated; instead, sound contrasts are made using only the lexical representation of words. In this case, the interaction between sound contrast and neighborhood density would be the result of task difficulty: dissimilar sound contrasts are easy enough that increasing word density does not increase the already highly accurate performance.

In line with past work (De Cara \& Goswami, 2003) the participants with the larger vocabularies were those whose phoneme awareness performance was affected by sound similarity and neighborhood density. Those with smaller vocabularies showed no effect of sound similarity or neighborhood density on performance. Interestingly the groups had similar overall accuracy levels on the odd-one-out task. In other words, vocabulary differences, not the ability to complete the task, were the driving force behind performance differences. According to the lexical restructuring model, the relative number of vocabulary words in one's lexicon is very likely to mediate a lexical characteristic such as neighborhood density. As a child's vocabulary expands, his/her lexical neighborhoods become denser (Charles-Luce \& Luce, 1990). It follows then that density effects on phoneme awareness could emerge as a threshold of lexical density is reached in a lexicon. It is less clear how vocabulary acquisition would mediate the impact of a phonological characteristic, like sound-contrast similarity, on phoneme awareness performance. Keep in mind, though, that the children in this study, as well as those in De Cara and Goswami (2003), were typically developing with age-appropriate vocabulary scores. Thus, it is not that case that we are comparing those with typical vocabulary learning with those who have vocabulary learning difficulties.

It is important to note that our results, although in line with past work on vocabulary effects on phoneme awareness, appear to be in opposition of results found when examining a different phonological task, nonword repetition. Studies of nonword repetition consistently find that as vocabulary increases lexical influences on nonword repetition are muted (e.g., Edwards, Beckman, \& Munson, 2004; Munson, Kurtz, \& Windsor, 2005). We believe this difference in vocabulary effects on phonological tasks is resultant of task differences. Nonword repetition is an implicit task requiring very little, if any, conscious reflection of the repeated sounds; alternatively, phoneme deletion requires explicit awareness of sounds. Future studies should explore the impact of vocabulary development on both implicit and explicit phonological task performance. A closer inspection of task performance, especially in the same children, may reveal similar lexical restructuring effects on both tasks; however vocabulary influences may be present at different points in development for each task. That is, an implicit task such as nonword repetition which relies on sublexical units of sound may benefit from lexical restructuring at an earlier time point in vocabulary development. This hypothesis is supported by work showing that children with language impairment, who by definition have reduced vocabulary, evidenced lexical influences on non- 
word repetition compared to their age-matched peers with high vocabulary skills (Munson et al., 2005).

Again related to neighborhood density, we explain our dense word advantage on phoneme awareness in terms of lexical restructuring, however acoustic characteristics could have, in part, influenced our results. Several recent studies have shown words from dense neighborhoods are produced acoustically more distinctly than those from sparse neighborhoods (e.g., Munson \& Solomon, 2004; Wright, 2004). Although we ensured that the words in our tasks did not differ in overall duration, we did not equate or measure their acoustic distinctiveness. Acoustic characteristics of our words in dense neighborhoods may, in part, explain the effect of neighborhood density on task performance insomuch as distinctiveness of productions influences one's ability to reflect consciously on speech sounds (e.g., complete a phoneme awareness task). Acoustic distinctiveness does not explain why our children with high vocabularies were the children in our study who evidenced a dense word advantage on phoneme awareness. Nonetheless, further work is needed to disentangle the effect of acoustic clarity versus neighborhood density on phoneme awareness before one can definitively say that lexical restructuring is the reason for the dense word advantage noted in this study and others.

\section{Caveats and Future Directions}

Two important caveats require attention and should spawn future work. First, although test word sets were constructed to differ in only sound similarity and neighborhood density, they differed in other ways that may have affected performance. For example, when gathering picture stimuli for the test sets, we noted that the words differing in neighborhood density also differed in imageability: dense words were more imageable than sparse words. Imageability was a factor that we could not control while holding other characteristics constant. Imageability, however, could have influenced the participants' ability to hold the word sets in memory. Another item characteristic that correlated with neighborhood density was phonotactic probability (Vitevitch \& Luce, 2004). Although the lexical restructuring model focuses on neighborhood density as the impetus for increased phonemic specification in words, it could be that more frequent sounds have more specified representations. Moreover, in the similar contrast conditions, all sounds differed by 1 distinctive feature. Some differed by voicing, others by manner, and others by place. In many cases, though, the sound contrasts in item sets across neighborhood density conditions - dense vs. sparse word sets - were the same. Nonetheless, studies have shown that voicing contrasts are more difficult than manner or place contrasts (e.g., Treiman et al.,
1998). Note that there were more voicing contrasts than manner or place contrasts in the similar-sparse condition compared to the similar-dense condition. Visual inspection of item level data - contained in Appendix A - show that voicing contrasts are not the most difficult across conditions. Thus, it is unlikely that the increased number of voicing contrasts in the similar-sparse condition is the reason that that condition is the most difficult. In a similar vein, orthographic consistency was not controlled when selecting word sets. A visual inspection of the stimuli spellings make it clear that some words had more consistent grapheme to phoneme links. This consistency, or lack thereof, could have impacted performance. Indeed studies have shown that grapheme to phoneme consistency influences performance on phoneme awareness tasks in adults (e.g., Castles, Holmes, Neath, \& Kinoshita, 2003). Lastly, the word-level characteristics of interest, sound-contrast similarity and neighborhood density, are on a continuum. In this study we grouped word sets dichotomously. A stronger test of these characteristics' influence would take advantage of the inherent variability in these metrics to better explain phoneme awareness performance. The challenge for future studies will be to disentangle the influence of many word characteristics - phonological, lexical, orthographic, and semantic - on the full range of phoneme awareness performance.

The second caveat involves task difficulty. Within current models of early identification, which often involve multiple measurement points, it is imperative to: 1) decrease false positive rates when using phoneme awareness tests to identify reading risk, and 2) create equated multiple measures of phoneme awareness to accurately measure improvement in this skill over time. A first step in this process is to identify item characteristics associated with performance in typically developing children. The next step would be to determine how item characteristics impact phoneme awareness performance in those who have reading impairments and those who are at risk for reading impairment. Very few children - 21 out of the 45 tested - could complete our odd-one-out task above chance. This is a problem when the goal is to create a test that is aimed at early identification. Phoneme awareness, however, is a unidimensional construct (Anthony et al., 2002; Schatschneider, Francis, Foorman, Fletcher, \& Mehta, 1999): children draw from the same pool of information to complete phoneme awareness tasks, but the tasks that are best able to tap that pool differ across age and ability level. Future studies will have to find the best task to quantify phoneme awareness in children with both typical and deficient phoneme awareness - both high and low vocabularies - to create an assessment that young children can complete, that takes advantage of item characteristics, and that accurately assesses reading risk. 


\section{Author Note}

The completion of this study was supported by research grants from the International Dyslexia Association (General Grant, PI: Hogan), the National Institutes of Health (DC9667, PI: Hogan), and the American Speech-Language-Hearing Association (AARC award; PI: Hogan). The following individuals contributed to stimuli preparation, data collection and data processing: Rebecca Volk, Elise Benadom, Tarynn Ciechoski, Marianne Crocovaner, Analydia Gonzales, Tina Meyers, Serena Singh, Amy Pellatz, Jillian McCarthy. We thank three anonymous reviewers, named reviewer Benjamin Munson, and Editor Jennifer Thomson for helpful feedback on the manuscript. We thank the children, families, and school staff who participated in this study.

Contact author: Tiffany P. Hogan, Department of Special Education and Communication Disorders, University of Nebraska - Lincoln, 318D Barkley, Lincoln, NE 68583, thogan2@unl.edu.

\section{Endnote}

${ }^{1}$ Grouping participants as high or low according to receptive vocabulary raw score resulted in a similar 3way interaction, whereas grouping participants as high or low according to phonological awareness raw and standard scores did not result in a statistically significant interaction.

\section{References}

Adams, M. J. (1990). Beginning to read: Thinking and learning about print. Cambridge, MA: MIT Press.

Anthony, J.L., Lonigan, C.J., Burgess, S.R., Driscoll, K., Phillips, B.M., \& Cantor, B.G. (2002). Structure of preschool phonological sensitivity: Overlapping sensitivity to rhyme, words, syllables, and phonemes. Journal of Experimental Child Psychology, 82, 65-92.

ASHA. (1997). Guidelines for audiologic screening. Rockville, MD: Author.

Bradley, L., \& Bryant, P. (1983). Categorizing sounds and learning to read: A causal connection. Nature, 301, 419-421.

Brownell, R. (2000a). Expressive One-Word Picture Vocabulary Test. Novato, CA: Academic Therapy Publications.

Brownell, R. (2000b). Receptive One-Word Picture Vocabulary Test. Novato, CA: Academic Therapy Publications.

Castles, A., Holmes, V. M., Neath, J., \& Kinoshita, S. (2003). How does orthographic knowledge influence performance on phonological awareness tasks? Quarterly Journal of Experimental Psychology, 56A, 445-467.
Catts, H. W. (1986). Speech production/phonological deficits in reading disordered children. Journal of Learning Disabilities, 19, 504-508.

Catts, H. W. (1989). Speech production deficits in developmental dyslexia. Journal of Speech and Hearing Disorders, 54, 422-428.

Catts, H. W., Fey, M. E., Zhang, X., \& Tomblin, J. B. (2001). Estimating the risk of future reading difficulties in kindergarten children: A research-based model and its clinical implementation. Language, Speech, and Hearing Services in Schools, 32, 38-50.

Catts, H., Wilcox, K., Wood-Jackson, C., Larrivee, L., \& Scott, V. (1996). Toward an understanding of phonological awareness. In C.K. Leong \& R.M. Joshi (Eds.). Crosslanguage studies of learning to read and spell: Phonologic and orthographic processing, Norwell, MA: Kluwer Academic Publishers.

Charles-Luce, J. \& Luce, P. A. (1990). Similarity neighbourhoods of words in young children's lexicons. Journal of Child Language, 17, 205-215.

Chin, S.B. (1996). The role of the sonority hierarchy in delayed phonological systems. In T. W. Powell (Ed.), $P a-$ thologies of speech and language: Contribution of clinical phonetics and linguistics, pp. 109-117. New Orleans, LA: International Clinical Phonetics and Linguistics Association.

Chomsky, N. \& Halle, M. (1968). The sound pattern of English. New York: Harper and Row.

De Cara, B. \& Goswami, U. (2003). Phonological neighbourhood density effects in a rhyme awareness task in 5-yearold children. Journal of Child Language, 30, 695-710.

Edwards, J., Beckman, M. E., \& Munson, B. (2004). The interaction between vocabulary size and phonotactic probability effects on children's production accuracy and fluency in nonword repetition. Journal of Speech, Language, and Hearing Research, 47, 421-436.

Elbro, C. (1996). Early linguistic abilities and reading development: A review and hypothesis. Reading and Writing: An Interdisciplinary Journal, 8, 453-485.

Elbro, C., \& Petersen, D. K. (2004). Long-term effects of phoneme awareness and letter sound training: An intervention study with children at risk for dyslexia. Journal of Educational Psychology, 96, 660-670.

Elbro, C., Neilsen, I., \& Petersen, D. K. (1994). Dyslexia in adults: Evidence for deficits in non-word reading and in the phonological representation of lexical items. Annals of Dyslexia, 44, 205-226.

Fowler A. (1991) How early phonological development might set the stage for phoneme awareness. In S. A. Brady \& D. P. Shankweiler (Eds.), Phonological processes in literacy: A tribute to Isabelle Y. Liberman, (pp. 97-117). Hillsdale, NJ: Lawrence Erlbaum Associates.

Gillon, G. T. (2004). Phonological awareness: From research to practice. New York: Guilford Press.

Goldman, R., \& Fristoe, M. (2000). Golman-Fristoe Test of Articulation - 2. Circle Pines, MN: American Guidance Service. 
Heath, S. M., \& Hogben, J. H. (2004). Cost-effective prediction of reading disabilities. Journal of Speech, Language, and Hearing Research, 47, 751-765.

Ho, C. S-H., \& Bryant, P. (1997). Learning to read Chinese beyond the logographic phase. Reading Research Quarterly, $32,276-289$.

Hogan, T. P., Catts, H. W., \& Little, T. D. (2005). The relationship between phonological awareness and reading: Implications for the assessment of phonological awareness. Language, Speech, and Hearing Services in Schools, 36, 285-293.

Jarvis, B. G. (2007). Direct RT research software (Version 2007). New York: Empirisoft.

Kucera, H., \& Francis, N. (1967). Computational analysis of present-day American English. Providence, RD: Brown University Press.

Lonigan, C. J., Wagner, R. K., Torgesen, J. K., \& Rashotte, C. A. (2007). Test of Preschool Early Literacy. Austin, TX: PRO-ED.

Luce, P. A., \& Pisoni, D. B. (1998). Recognizing spoken words: The neighborhood activation model. Ear $\mathcal{E}$ Hearing, 19, 1-36.

Luce, P. A., Goldinger, S. D., Auer, E. T., Jr., \& Vitevitch, M. S. (2000). Phonetic priming, neighborhood activation, and PARSYN. Perception and Psychophysics, 62, 615-625.

Mann, V. (1984). Longitudinal prediction and prevention of early reading difficulty. Annals of Dyslexia, 34, 115-136.

Metsala, J. L. (1999). Young children's phonological awareness and nonword repetition as a function of vocabulary development. Journal of Educational Psychology, 91, 3-19.

Metsala, J. L., \& Walley, A. C. (1998). Spoken vocabulary growth and the segmental restructuring of lexical representations: Precursors to phonemic awareness and early reading ability. In J. L. Metsala (Ed.), Word recognition in beginning literacy (pp. 89-120). Mahwah, NJ: Lawrence Erlbaum Associates.

Moe, A. J., Hopkins, C. J., \& Rush, R. T. (1982). The vocabulary of first-grade children. Springfield, IL: Thomas.

Munson, B. \& Solomon, N.P. (2004). The effect of phonological neighborhood density on vowel articulation. Journal of Speech, Language, and Hearing Research, 47, 1048-1058.

Munson, B., Kurtz, B. A., \& Windsor, J. (2005). The influence of vocabulary size, phonotactic probability, and wordlikeness on nonword repetitions of children with and without specific language impairment. Journal of Speech, Language, and Hearing Research, 48, 1033-1047.

Nusbaum, H. C., Pisoni, D. B., \& Davis, C. K. (1984). Sizing up the Hoosier mental lexicon: Measuring the familiarity of 20,000 words. (Research on Speech Perception

Progress Report No. 10). Bloomington, IN: Speech Research Laboratory, Psychology Department, Indiana University.

Olofsson, D. I., \& Wall, S. (1980). Reading and spelling skills in the first school year predicted from phonemic awareness skills in kindergarten. Scandinavian Journal of Psychology, 21, 159.
Reynolds, C. R., \& Kamphaus, R. W. (2002). Reynolds Intellectual Assessment Scales. Lutz, FL: Psychological Assessment Resources.

Scarborough, H. (2005). Developmental relationships between language and reading: Reconciling a beautiful hypothesis with some ugly facts. In H. Catts \& A. Kamhi (Eds.) Connections between language and reading disabilities. (pp. 3-24) Mahwah, NJ: Erlbaum.

Schatschneider, C., Francis, D. J., Foorman, B. R., Fletcher, J. M., \& Mehta, P. (1999). The dimensionality of phonological awareness: An application of item response theory. Journal of Educational Psychology, 91, 439-449.

Shankweiler, D., \& Liberman, I.Y. (1978). Reading behavior in dyslexia: Is there a distinctive pattern? Bulletin of the Orton Society, 28, 114-123.

Share, D. L., Jorm, A., Maclean, R., \& Matthews, R. (1984). Sources of individual differences in reading acquisition. Journal of Educational Psychology, 76, 1309-1324.

Storkel, H. L., \& Morrisette, M. L. (2002). The lexicon and phonology: Interactions in language acquisition. Language, Speech, and Hearing Services in Schools, 33, 24-37.

Swan, D., \& Goswami, U. (1997). Picture naming deficits in developmental dyslexia: The phonological representations hypothesis. Brain and Language, 56, 334-353.

Swanson, H. L., Trainin, G., Necoechea, D. M., \& Hammill, D. (2003). Rapid naming, phonological awareness, and reading: A meta-analysis of correlation evidence. Review of Educational Research, 73, 407-440.

Torgesen, J. K., Wagner, R. K., \& Rashotte, C. A. (1994). Longitudinal studies of phonological processing and reading. Journal of Learning Disabilities, 27, 276-286.

Treiman, R., Broderick, V., Tincoff, R., \& Rodriguez, K. (1998). Children's phonological awareness: Confusions between phonemes that differ only in voicing. Journal of Experimental Child Psychology, 68, 3-21.

Vitevitch, M. S. (2003). The influence of sublexical and lexical representations on the processing of spoken words in English. Clinical Linguistics and Phonetics, 17, 487-499.

Vitevitch, M. S., \& Luce, P. A. (2004). A web-based interface to calculate phonotactic probability for words and nonwords in English. Behavior Research Methods, Instruments, and Computers, 36, 481-487.

Walley, A. C., Metsala, J. L., \& Garlock, V. M. (2003). Spoken vocabulary growth: Its role in the development of phoneme awareness and early reading ability. Reading and Writing, 16, 5-20.

Wright, R. (2004). Factors of lexical competition in vowel articulation. In J. Local, R. Ogden, \& R. Temple (Eds.), Papers in Laboratory Phonology VI (pp. 26-50). Cambridge: Cambridge University Press.

Yavas, M. S., \& Core, C. W. (2001). Phonemic awareness of coda consonants and sonority in bilingual children. Clinical Linguistics and Phonetics, 15, 35-39.

Yopp, H. K. (1988). The validity and reliability of phonemic awareness tests. Reading Research Quarterly, 13, 159-177. 
Appendix A. Odd-One-Out Task Word Sets

\begin{tabular}{|c|c|c|c|c|c|c|c|}
\hline Word Set & Condition & $\begin{array}{l}\text { Sound } \\
\text { Contrast }\end{array}$ & $\begin{array}{l}\# \text { of } \\
\text { Distinctive } \\
\text { Feature } \\
\text { Different }\end{array}$ & $\begin{array}{l}1^{\text {st }} \text { word } \\
\text { Neighborhood } \\
\text { Density }\end{array}$ & $\begin{array}{l}2^{\text {nd }} \text { word } \\
\text { Neighborhood } \\
\text { Density }\end{array}$ & $\begin{array}{l}3^{\text {rd }} \text { word } \\
\text { Neighborhood } \\
\text { Density }\end{array}$ & $\begin{array}{l}\# \text { correct } \\
\text { across } \\
\text { children } \\
(\mathrm{n}=21)\end{array}$ \\
\hline sun-sick-thin & Similar-Dense & $/ \mathrm{s} /-/ \int /$ & 1 & 21 & 22 & 12 & 12 \\
\hline vote-fire-face & Similar-Dense & $/ \mathrm{f} /-/ \mathrm{v} /$ & 1 & 10 & 13 & 17 & 12 \\
\hline seal-seat-thick & Similar-Dense & $|s /-| \theta \mid$ & 1 & 24 & 25 & 12 & 18 \\
\hline knight-nose-mail & Similar-Dense & $/ \mathrm{n} /-/ \mathrm{m} /$ & 1 & 21 & 14 & 27 & 15 \\
\hline chair-chain-ship & Similar-Dense & $/ \mathrm{t} \int /-/ \int /$ & 1 & 18 & 14 & 15 & 17 \\
\hline gas-race-worth & Similar-Dense & $/ \mathrm{s} /-/ \theta /$ & 1 & 12 & 18 & 10 & 14 \\
\hline job-red-kid & Similar-Dense & $/ \mathrm{d} /-/ \mathrm{b} /$ & 1 & 12 & 19 & 17 & 17 \\
\hline beach-wish-touch & Similar-Dense & $/ \mathrm{t} \int /-/ \delta /$ & 1 & 14 & 11 & 11 & 11 \\
\hline book-rock-leg & Similar-Dense & $/ \mathrm{k} /-/ \mathrm{g} /$ & 1 & 15 & 17 & 12 & 14 \\
\hline \multirow[t]{4}{*}{ game-man-phone } & Similar-Dense & $/ \mathrm{n} /-/ \mathrm{m} /$ & 1 & 17 & 20 & 19 & 15 \\
\hline & & M feature difference & 1 & & M word density & 16.30 & $\mathrm{M}=6.90$ \\
\hline & & $\mathrm{SD}$ & 0 & & $\mathrm{SD}$ & 4.62 & $\mathrm{SD}=1.84$ \\
\hline & & range & 1 & & range & $10-27$ & \\
\hline third-size-search & Similar-Sparse & $|s /-| \theta \mid$ & 1 & 6 & 9 & 8 & 11 \\
\hline thought-serve-theme & Similar-Sparse & $|\theta|-|s|$ & 1 & 7 & 7 & 8 & 14 \\
\hline voice-foot-firm & Similar-Sparse & $/ \mathrm{f} /-/ \mathrm{v} /$ & 1 & 5 & 9 & 8 & 11 \\
\hline church-choose-sure & Similar Sparse & $/ \mathrm{t} \int /-/ \delta /$ & 1 & 6 & 7 & 8 & 16 \\
\hline fish-voice-faith & Similar-Sparse & $/ \mathrm{f} /-/ \mathrm{v} /$ & 1 & 9 & 5 & 8 & 12 \\
\hline south-youth-guess & Similar-Sparse & $|\theta|-|\mathrm{s}|$ & 1 & 3 & 4 & 8 & 12 \\
\hline love-give-knife & Similar-Sparse & $/ \mathrm{v} /-/ \mathrm{f} /$ & 1 & 8 & 5 & 5 & 7 \\
\hline fish-church-search & Similar-Sparse & $/ \mathrm{t} \int /-/ \int /$ & 1 & 9 & 5 & 8 & 14 \\
\hline earth-mouth-choice & Similar-Sparse & $|\theta|-|s|$ & 1 & 7 & 7 & 3 & 13 \\
\hline \multirow[t]{4}{*}{ move-knife-safe } & Similar-Sparse & $/ \mathrm{f} /-/ \mathrm{v} /$ & 1 & 8 & 5 & 9 & 13 \\
\hline & & M feature difference & 1 & & M word density & 6.80 & $M=5.86$ \\
\hline & & $\mathrm{SD}$ & 0 & & $\mathrm{SD}$ & 1.81 & $\mathrm{SD}=2.15$ \\
\hline & & range & 1 & & range & $3-9$ & \\
\hline year-team-tall & Dissimilar-Dense & $/ \mathrm{t} /-/ \mathrm{j} /$ & 8 & 15 & 13 & 20 & 19 \\
\hline man-meat-hat & Dissimilar-Dense & $/ \mathrm{m} /-/ \mathrm{t} /$ & 8 & 20 & 21 & 29 & 14 \\
\hline nine-hole-head & Dissimilar-Dense & $/ \mathrm{h} /-/ \mathrm{n} /$ & 9 & 16 & 22 & 19 & 13 \\
\hline take-talk-week & Dissimilar-Dense & $/ \mathrm{t} /-/ \mathrm{w} /$ & 9 & 20 & 18 & 17 & 18 \\
\hline phone-fell-name & Dissimilar-Dense & $/ \mathrm{f} /-/ \mathrm{n} /$ & 7 & 19 & 20 & 13 & 17 \\
\hline half-moon-sun & Dissimilar-Dense & $/ \mathrm{n} /-/ \mathrm{f} /$ & 7 & 15 & 16 & 21 & 14 \\
\hline sick-check-rain & Dissimilar-Dense & $/ \mathrm{k} /-/ \mathrm{n} /$ & 7 & 22 & 11 & 22 & 12 \\
\hline wife-line-run & Dissimilar-Dense & $/ \mathrm{n} /-/ \mathrm{f} /$ & 7 & 10 & 22 & 20 & 13 \\
\hline learn-mean-talk & Dissimilar-Dense & $/ \mathrm{n} /-/ \mathrm{k} /$ & 7 & 14 & 18 & 18 & 10 \\
\hline \multirow[t]{4}{*}{ big-pass-race } & Dissimilar-Dense & $/ \mathrm{s} /-/ \mathrm{g} /$ & 8 & 18 & 16 & 18 & 15 \\
\hline & & M feature difference & 7.7 & & M word density & 18.1 & $M=6.90$ \\
\hline & & $\mathrm{SD}$ & 0.82 & & $\mathrm{SD}$ & 3.87 & $\mathrm{SD}=1.64$ \\
\hline & & range & $7-9$ & & range & $10-29$ & \\
\hline young-youth-teeth & Dissimilar-Sparse & $/ \mathrm{j} /-/ \mathrm{t} /$ & 8 & 4 & 4 & 8 & 12 \\
\hline house-knife-neck & Dissimilar-Sparse & $/ \mathrm{n} /-/ \mathrm{h} /$ & 9 & 5 & 5 & 9 & 17 \\
\hline good-guess-size & Dissimilar-Sparse & $/ \mathrm{g} /-/ \mathrm{s} /$ & 8 & 6 & 8 & 9 & 17 \\
\hline south-safe-give & Dissimilar-Sparse & $/ \mathrm{s} /-/ \mathrm{g} /$ & 8 & 3 & 9 & 5 & 16 \\
\hline wheel-watch-teeth & Dissimilar-Sparse & $/ \mathrm{w} /-/ \mathrm{t} /$ & 9 & 6 & 5 & 8 & 15 \\
\hline roof-safe-join & Dissimilar-Sparse & $/ \mathrm{f} /-/ \mathrm{n} /$ & 8 & 8 & 9 & 5 & 14 \\
\hline dog-use-house & Dissimilar-Sparse & $/ \mathrm{s} /-/ \mathrm{g} /$ & 7 & 7 & 6 & 5 & 15 \\
\hline firm-them-church & Dissimilar-Sparse & $/ \mathrm{m} /-/ \mathrm{t} \int /$ & 8 & 8 & 5 & 5 & 14 \\
\hline watch-search-theme & Dissimilar-Sparse & $/ \mathrm{t} \int /-/ \mathrm{m} /$ & 5 & 5 & 8 & 8 & 14 \\
\hline \multirow[t]{4}{*}{ join-knife-roof } & Dissimilar-Sparse & $/ \mathrm{f} /-/ \mathrm{n} /$ & 5 & 5 & 5 & 8 & 15 \\
\hline & & M feature difference & 7.50 & & M word density & 6.37 & $\mathrm{M}=7.09$ \\
\hline & & $\mathrm{SD}$ & 1.43 & & $\mathrm{SD}$ & 1.79 & $\mathrm{SD}=1.97$ \\
\hline & & range & $5-9$ & & range & $3-9$ & \\
\hline
\end{tabular}

